\title{
STUDIES ON EARLINESS GENES IN RICE, WITH SPECIAL REFERENCE TO ANALYSIS OF ISOALLELES AT THE E LOCUS
}

\author{
KUO-HAI TSAI ${ }^{1)}$ \\ Food Crops Research Institute, National Chung-Hsing University \\ Taichung, Taiwan 400, Republic of China
}

Received February 25, 1976

The genetic control of heading time in rice (Oryza sativa L.) has been reported by many workers. It is known that some genes control photoperiodism (Chandraratna 1955; Kawase and Murata 1958; Yu and Yao 1967), whereas others regulate the duration of vegetative growth (Chang et al. 1969). The genes dealt with in this paper are those regulating the duration of vegetative growth or the time of floral initiation in photoperiod-insensitive strains. In the previous work cited above, genic analysis was based on the distribution of heading dates in hybrid populations. By this method, however, genes producing a strong effect could only be detected. On the other hand, by the biometrical methods, only the overall additive and non-additive genic effects and other parameter values could be estimated. The effects of individual genes on the development and floral initiation have largely remained obscure.

With the hope of overcoming these difficulties in the genetic study of quantitative characters, the present author has attempted to isolate individual genes in an identical genetic background by recurrent backcrossing and selection. A representative Ponlai (or Horai, improved Japonicas in Taiwan) variety, Taichung 65, was exclusively used as the recurrent parent. This cultivar, selected from hybridization between two Japanese varieties around 1925, is commonly grown in Taiwan and some other subtropical countries. It is practically insensitive to photoperiod and adapted to both the winter (first crop, seeded in January-February) and the summer (second crop, seeded in July) cropping seasons in Taiwan. As the donor parent, early-maturing rice cultivars and mutant lines induced from Taichung 65 were used, and various isogenic lines were established. Experiments with the isogenic lines proved that the genes for earliness from different donor parents were at the same locus symbolized $E$ and had similar heading-advancing effects. Yet they significantly differed from one another when compared in detail.

In this paper, data showing differences among the $E$ alleles are presented, which suggest that the $E$ locus consists of a complementation group of several subloci.

1) Present address: Casilla No. 16 Oficina de Correos, Ciudad de Treinta y Tres, Uruguay. Correspondence as to this paper may also be addressed to: Dr. H. I. Oka, National Institute of Genetics, Misima, 411 Japan. 


\section{AN OUTLINE OF EARLIER PUBLICATIONS}

To provide background information to the reader, papers so far published in Taiwan on the isogenic lines (Tsai and Oka 1965, 1966, 1968, 1970; Tsai 1971a, b, 1973, 1974, etc.) and the author's doctoral thesis (Tsai 1972) are briefly summarized below, as the papers are rather fragmentary and scattered in periodicals and governmental reports with limited circulation.

A pure line of Taichung 65 (abridged as T65; progeny of a self-pollinated single plant) was used as the recurrent parent. The mean number of days to heading of T65 is about 120 in the winter and about 85 in the summer season. Tatong-tsailai (A) from northern China and Bozu 5 (B) from northern Japan were used as the donor parents. Their mean numbers of days to heading were 72 and 53 for $\mathrm{A}$, and 92 and 64 for $\mathrm{B}$ in the winter and summer seasons, respectively. In each backcross generation, a few plants heading appreciably earlier than T65 were selected for further crossing. Isogenic early-maturing lines were selected first from among $\mathrm{B}_{7} \mathrm{~F}_{3}$ lines. Two of them, $\mathrm{A} 3_{7}$ and $\mathrm{B} 96_{7}$, both heading about 10 days earlier than T65, had earliness genes $E^{\text {a }}$ (from $\mathrm{A})$ and $E^{\mathrm{b}}$ (from $\mathrm{B}$ ), respectively (the suffix, 7 , indicates selection from $\mathrm{B}_{7}$ ). The $E$ genes were dominant over their recessive allele, $e$, carried by T65 (Tsai and Oka 1965).

Crossing experiments with isogenic marker lines of T65 (established by backcrossing in parallel with the breeding of early-maturing lines) showed that $E$ was linked with la (lazy habit), recombination value being about 36 percent (Tsai 1972, 1973). This indicates that the $E$ locus belongs to the 8th linkage group of Takahashi (1964). Backcrossing was continued up to the 20th generation for more "purification" of the isogenic lines, and lines $\mathrm{A} 3_{20}, \mathrm{~B} 96_{20}$, etc. were obtained.

Further, two similarly early-maturing mutant lines induced from T65, I123 and I190, were found to carry a dominant earliness gene at the $E$ locus (Tsai 1971a). I123 was a selection from the $\mathrm{M}_{3}$ progeny of irradiated seeds with $25 \mathrm{kR}$ gamma-rays; I190 was from the $\mathrm{M}_{3}$ progeny with $40 \mathrm{kR}$ X-rays. In order to remove other genic changes than that at $E$, they were backcrossed with T65 five times, and $\mathrm{I}_{123_{5}}, \mathrm{I} 190_{5}$, etc. were obtained. Backcrossing five times may be enough for making the mutant lines isogenic, as a line from an irradiated seed is expected to have a small number of genic changes.

In addition, in order to observe the distribution of $E$ genes in different rice cultivars, backcross-derivatives of six early-maturing Japonicas with T65 (3 or 4 times with T65) were examined; the early-maturing cultivars used were four Japanese natives (Ebisu, Yachikogane, Yubo-asahi, and Kissin) and two Ponlais (Taichung 180 and Taichung 186). The crosses of the derivatives with $\mathrm{T} 65$ and $\mathrm{A} 3_{7}$ or $\mathrm{B} 96_{7}$ proved that all the cultivars used had a dominant earliness gene at the $E$ locus. Kissin was sensitive to photoperiod, and carried a dominant photo-sensitive gene ( $P s$, independent of $E$ ) in addition to an $E$ allele (Tsai and Oka 1966). It was postulated that the $E$ genes would be commonly distributed in Japonica varieties grown in temperate zones.

Modifier genes. Some isogenic lines $\left(\mathrm{A} 4_{7}, \mathrm{~B} 20_{7}\right.$, etc.) whose heading dates were about 10 days earlier than those of $A 3_{7}$, etc. were found to have a recessive gene $m$ in 
addition to $E$ (Tsai and Oka 1970). The $m$ locus was independent of $E$, and there were found three alleles, $m^{\mathrm{a}}$ from donor parent $\mathrm{A}, m^{\mathrm{b}}$ from $\mathrm{B}$, and $m^{+}$(dominant) in T65. The prominent effect of $m^{\mathrm{a}}$ and $m^{\mathrm{b}}$ was epistatic intensification of the effect of $E$ genes. As $m^{\text {a }}$ and $m^{\text {b }}$ showed no significant difference in their effect, they are commonly designated as $m$ unless their distinction is deemed necessary. When combined with $e$, the $m$ gene had no effect in summer $\left(e e m m=e e m^{+} m^{+}\right)$but moved up the heading time a few days in the winter season (eemm earlier than $\left.e e m^{+} m^{+}\right)$, as will be mentioned later.

There can be other genes than $E$ and $m$ controlling heading time in the crosses between $\mathrm{T} 65$ and the donor parents, $\mathrm{A}$ and $\mathrm{B}$. To estimate the effect of those residual genes, the $\mathrm{F}_{2}$ and $\mathrm{F}_{3}$ data from $\mathrm{T} 65 \times \mathrm{A}$ (tested in winter season) were analysed by Mather's (1949) biometrical method (Tsai 1972). The results indicated that there were $2.1\left(\mathrm{~K}_{2}\right)$ to $4.2\left(\mathrm{~K}_{1}\right)$ effective factors and the genic interaction was highly significant. However, the estimate of additive genetic variance, $D=62.59 \pm 4.41$, was smaller than the value expected from the homozygotic effects of $E^{\text {a }}: e$ and $m: m^{+}, 75.63$; thismight have resulted in an overestimation of $\mathrm{K}_{1}$ value. Further, a comparison of $\mathrm{F}_{2}$ distributions of heading time among crosses showed that $\mathrm{A} 3_{7}\left(E^{\mathrm{a}} E^{\mathrm{a}} m^{+} m^{+}\right) \times \mathrm{A} 4_{7}\left(E^{\mathrm{a}} E^{\mathrm{a}} m m\right)$ generated a significantly larger $\mathrm{F}_{2}$ genetic variance than $\mathrm{A} 3_{7} \times \mathrm{A}\left(E^{\mathrm{a}} E^{\mathrm{a}} \mathrm{mm}\right.$ and other genes). Namely, the $F_{2}$ genetic variances in the former cross where only $m^{+}: m$ segregated were 38.1 and 59.3 in the winter and summer seasons, respectively, and these values were close to those expected from the homo- and heterozygotic effects of $m^{+}: m$, 36.4 and 57.6. The $\mathrm{F}_{2}$ genetic variances in $\mathrm{A} 3_{7} \times \mathrm{A}$ where not only $m^{+}: m$ but other genes also segregated were 11.7 and 23.9 in the winter and summer seasons, respectively. A similar trend was also found in the cross between T65 and B. This suggests that the residual genes remaining unanalysed have a buffering or canalizing effect when recombined, reducing the genetic variance generated by $E$ and $m$. They may be called "polygenes", but their effects are by no means additive.

Pleitotropic effects. Comparisons of isogenic lines enabled us to observe the effects of genes $E$ and $m$ on organ development, grain yield and yield stability (Tsai and Oka 1965, 1968, 1970; Tsai 1974). Generally, the $E$ genes did not affect the growth and development before floral initiation. They moved up the time of floral initiation about 7 days and shortened the period from floral initiation to heading by 2 to 3 days. They then reduced the length of internodes, leaves and panicles which were formed after floral initiation, resulting in a particular allometric pattern. The fourth and fifth internodes from the top were shortened to about 60 and 30 percent of those in $T 65$, respectively. The length of upper internodes, the blades and sheaths of first and second leaves (from the top), and of the panicle was reduced by 5 to 10 percent. The reduction of spikelet number per panicle by the $E$ gene was 2 (winter season) to 10 (summer season) percent. Seed fertility, length and width of spikelets, and 100 grain weight remained unaffected. In these respects, no significant differences were found among different $E$ alleles. The $m$ gene was found to intensify these pleiotropic effects of the $E$ gene (Tsai and Oka 1970).

By fitting logistic equations to the data on organ elongation, it was found that the $E$ gene increased the elongation rates (cm/day) of panicle and upper internodes, but 
shortened the duration of elongating period of each organ and the time span from floral initiation to heading (Tsai and Oka 1968). Further, the partial regressions of days to heading on mean temperatures of the periods before and after floral initiation (both days and temperatures in logarithms) were computed to obtain temperature constants for the growth in respective periods. The results proved that the $E$ gene reduced the sensitivity to temperature in the period before floral initiation but increased it in the period after floral initiation (Tsai and Oka 1968). Moreover, tests of earlymaturing isogenic lines at different fertilizer levels indicated that their grain yield at an optimal level $\left(8-5-4 \mathrm{NPK}, \mathrm{g} / \mathrm{m}^{2}\right)$ was not inferior to that of $\mathrm{T} 65$ (about $4.5 \mathrm{ton} / \mathrm{ha}$ ), but tended to be reduced by too low or too high fertilizer doses more violently than in T65. In other words, the $E$ gene reduced the adaptive range or latitude of the plants to nutritional conditions (Tsai and Oka 1965; Tsai 1974).

The early-maturing isogenic lines, $\mathrm{A} 3_{7}$ and $\mathrm{B} 96_{7}$, were repeatedly tested at different locations (District Agricultural Improvement Stations) in Taiwan. Generally, the $E$ gene slightly reduced the grain yield of T65 in the winter seasons and by 5 to 10 percent in the summer seasons. In the northern part of Taiwan, however, the $E$ lines gave higher yield than $\mathrm{T} 65$ in the summer season (Tsai and Oka 1968). It was also found that the $E$ gene did not change the yield stability of T65 as shown by the regression on environmental means. This suggested the usefulness of backcrossing method in breeding early-maturing rice varieties.

\section{MATERIALS AND METHODS}

The isogenic lines used for this study were as follows:

1) $E$ lines, heading about 10 days earlier than $\mathrm{T} 65-\mathrm{A} 3_{7}, \mathrm{~A} 3_{10}, \mathrm{~A} 3_{20}$, etc., derived from different backcross generations shown by the suffix, carry an $E$ allele from donor parent $\mathrm{A}$ (symbolized $E^{\mathrm{a}(7)}, E^{\mathrm{a}(10)}, E^{\mathbf{a}(20)}$, etc., respectively). In the same manner, $\mathrm{B} 96_{7}$, etc. carry $E^{\text {b }}$ alleles from donor parent B. I123, I123, etc. with $E^{r}$ and I190, I190, etc. with $E^{\mathrm{x}}$ are isogenic mutant lines of $\mathrm{T} 65$ as already mentioned.

2) Lines with $m-\mathrm{A}_{4}$ having $E^{\mathrm{a}(7)}$ and $m^{\mathrm{a}}$ is a selection from the $\mathrm{B}_{7} \mathrm{~F}_{2}$ of an $\mathrm{F}_{4}$ line (A36) from T65 $\times$ A. Its heading was about 20 days earlier than that of T65. A458 having $e$ and $m^{\mathrm{a}}$ was obtained from the $\mathrm{F}_{3}$ of $\mathrm{T} 65 \times \mathrm{A} 4_{7} . \quad \mathrm{B} 172_{7}$ is a sib line of $\mathrm{B}_{6} 6_{7}$ having $e$ and $m^{\mathrm{b}}$. B40-20 also with $e$ and $m^{\mathrm{b}}$ was obtained from the $\mathrm{F}_{2}$ of $\mathrm{A}_{2} 4_{7}\left(E^{\mathrm{a}} m^{\mathrm{b}}\right) \times$ T65 $\left(\mathrm{em}^{+}\right) . \quad \mathrm{B} 20_{7}$ with $E^{\mathrm{b}(7)}$ and $m^{\mathrm{b}}$ was selected from $\mathrm{B} 96_{7} \times \mathrm{B}_{172}$.

3) Late-heading sib lines-During the backcrossing experiment, a number of sib lines heading one or two days earlier than T65 (later than $E$ lines) were selected and examined. Though some of them had the same genotype as of T65 $\left(\mathrm{em}^{+}\right)$or $e$ and $m$ like $\mathrm{B} 172_{7}$, others exhibited a particular genetic behavior. Namely, when intercrossed, they produced a few early-heading offtypes in the $F_{2}$. Those were $A 3_{7} L, B 96_{7} L, B 96_{15} L$, I190 $\mathrm{L}$, etc. obtained as the sibs of respective lines.

All the above-listed lines can be regarded as possessing the same genotype as of T65 except for a short chromosomal segment containing respective genes. They also have the same cytoplasm as of T65 since it was used as the maternal parent in the initial and many subsequent crosses. 
Experiments were carried out in an irrigated paddy field (loamy clay, covered by wirenet) of the Chung-Hsing University at Taichung $\left(24^{\circ} \mathrm{N}\right)$. Seeds were germinated in petri-dishes, and the seedlings raised in pots or in a seed-bed for two (summer) to four (winter) weeks were transplanted into the field at a $25 \times 25 \mathrm{~cm}$ spacing with a single plant per hill. The dosage of fertilizers applied was $8-5-4 \mathrm{~N}-\mathrm{P}_{2} \mathrm{O}_{5}-\mathrm{K}_{2} \mathrm{O}\left(\mathrm{g} / \mathrm{m}^{2}\right.$, basal dressing except for a half of $\mathrm{N}$ top-dressed at mid-tillering and heading stages). The date of emergence of the first panicle in each plant was recorded as its heading time. Like other metric characters, heading date or the number of days to heading is always subjected to environmental fluctuation; its standard deviation for single measurements was usually 1.2 to 2 days. For determining the days to heading of a line, mean for more than 25 plants was used, and the significance of differences between lines was tested either by $t$ or by LSD obtained from an analysis of variance of the data.

\section{RESULTS}

Structure of the $E$ locus. Comparisons of the days to heading among $E$ lines showed that $\mathrm{A} 3_{7}$ was significantly earlier than $\mathrm{B} 96_{7}$, and $\mathrm{A} 3_{10}$ was significantly earlier

Table 1. Comparison of days to heading and plant height among $E$ lines derived from different backcross generations

(a) $\mathrm{BC}_{7}: \mathrm{BC}_{10}$, mean for 6 experiments in 1967 winter

\begin{tabular}{|c|c|c|c|c|c|c|c|c|c|}
\hline Line & Genotype & $\begin{array}{l}\text { Days to } \\
\text { heading }\end{array}$ & $\begin{array}{l}\text { Height } \\
(\mathrm{cm})\end{array}$ & $\mathrm{A} 3_{7}$ & $\mathrm{~A} 3_{10}$ & $\begin{array}{c}\text { Differenc } \\
\text { B } 96_{7}\end{array}$ & $\begin{array}{l}\text { e from: } \\
\text { B96 }_{10}\end{array}$ & I123 & I190 \\
\hline $\mathrm{T} 65$ & $e$ & $0(=112.7)$ & (108.3) & $(\mathrm{H}$ & ht) & & & & \\
\hline $\mathrm{A} 3_{7}$ & $E^{\mathbf{a}(7)}$ & -12.7 & -10.9 & (Days) & ns & $* *$ & & $* *$ & $\mathrm{~ns}$ \\
\hline $\mathrm{A} 3_{10}$ & $E^{\mathrm{a}(10)}$ & -11.6 & -9.9 & * & & & $* *$ & $* *$ & ns \\
\hline B96 $6_{7}$ & $E^{\mathrm{b}(7)}$ & -10.0 & -6.5 & $* *$ & & & $\mathrm{~ns}$ & $* *$ & $* *$ \\
\hline $\mathrm{B} 96_{10}$ & $E^{\mathrm{b}(10)}$ & -9.2 & -5.0 & & $* *$ & ns & & $* *$ & $* *$ \\
\hline I123 & $E^{r}$ & -12.3 & -17.0 & ns & $\mathrm{ns}$ & $* *$ & $* *$ & & $* *$ \\
\hline $\mathrm{I} 123$ & $E^{\mathrm{x}}$ & -12.9 & -11.5 & ns & ns & $* *$ & $* *$ & $\mathrm{~ns}$ & \\
\hline
\end{tabular}

Significance tested by ANOVA for each pair of comparisons,

** $1 \%$ level; * $5 \%$ level; ns Non-significant.

(b) Induced $E$ lines, mean for 4 experiments in 1970-72 winter

\begin{tabular}{|c|c|c|c|c|c|c|c|}
\hline Line & Genotype & $\begin{array}{l}\text { Days to } \\
\text { heading }\end{array}$ & $\underset{(\mathrm{cm})}{\text { Height }}$ & Line & Genotype & $\begin{array}{l}\text { Days to } \\
\text { heading }\end{array}$ & $\underset{(\mathrm{cm})}{\text { Height }}$ \\
\hline $\mathrm{T} 65$ & $e$ & $0(=125.2)$ & $(118.5)$ & I190 & $E^{\mathrm{X}}$ & -11.1 & -9.3 \\
\hline $\mathrm{I} 123$ & $E^{r}$ & -11.3 & -13.4 & $\mathrm{I} 190_{2}$ & $E^{\mathrm{X}(2)}$ & $-10.0^{*}$ & $-2.5^{* *}$ \\
\hline $\mathrm{I} 123_{2}$ & $E^{\gamma(2)}$ & $-8.7^{* *}$ & -11.3 & $\mathrm{I} 190_{5}$ & $E^{\mathrm{X}(5)}$ & $-8.0^{* *}$ & $-4.2^{* *}$ \\
\hline $\mathrm{I} 123_{5}$ & $E^{\gamma(5)}$ & $-9.7^{* *}$ & $-5.9 * *$ & $\begin{array}{r}\text { LSD } 5 \% \\
1 \%\end{array}$ & & $\begin{array}{l}0.90 \\
1.22\end{array}$ & $\begin{array}{l}3.65 \\
4.81\end{array}$ \\
\hline
\end{tabular}

${ }^{*}, * *$ Significance of difference from the value of original line, I123 or I190. 
than $\mathrm{B} 6_{10}$ (Table 1). This indicates that $E^{\mathrm{a}}$ from donor parent $\mathrm{A}$ has a stronger heading-advancing effect than $E^{\mathrm{b}}$ from donor parent $\mathrm{B}$. The heading dates of induced mutant lines before backcrossing, I123 $\left(E^{r}\right)$ and I190 $\left(E^{\mathrm{x}}\right)$, were close to those of the lines with $E^{\mathrm{a}}$.

Comparisons among lines having an $E$ gene of the same origin but derived from different backcross generations showed that "purification" by backcrossing tended to reduce the heading-advancing effect of the $E$ genes (Table 1; Fig. 1). Significant differences showing this trend were found between lines with $E^{\mathrm{b}(7)}$ and $E^{\mathrm{b}(10)}, E^{\mathbf{X}(2)}$ and $E^{\mathbf{X}(5)}$, and between those with $E^{r(0)}$ and $E^{r(2)}$. This may be attributed to elimination of some genes linked with $E$, though the last case can also be explained by elimination of induced mutant genes at independent loci. Figure 1 shows further that the modifying effect of $m$ on $E$ tended to increase with the "purification" of $E$ alleles; this will be dealt with later.

When lines with different $E$ alleles were inter-crossed, the $\mathrm{F}_{1}$ plants showed dominance in the direction of earliness slightly, and the $\mathrm{F}_{2}$ populations had larger variances of the days to heading, some being significantly larger, than the self-pollinated parental lines (Table 2). This serves as another evidence for the postulation that the $E$ alleles are not identical even though they are similar. They may be regarded as isoalleles (alleles indistinguishable except by special tests, Allard 1960, p. 468).

In order to know what genes the late-heading sib lines have had, they were crossed in different combinations. Their crosses with $E$ lines gave a 3 early: 1 late ratio in the $\mathrm{F}_{2}$, indicating that they had a late-maturity allele at the $E$ locus. Their crosses with $\mathrm{T} 65(e e)$ showed no remarkable segregation in the $\mathrm{F}_{2}$ though the variances were

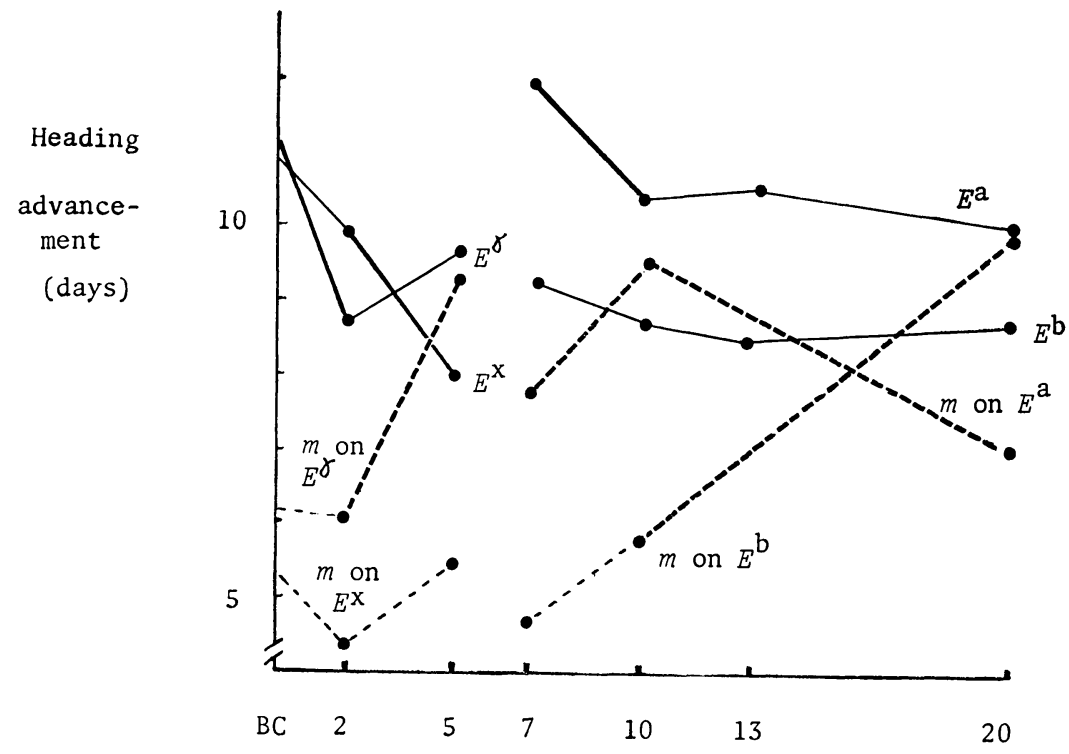

Fig. 1. Change in the effect of $E$ alleles with recurrent backcrossing. Solid lineHeading advancement of $E E m^{+} m^{+}$plants as compared with $e e m^{+} m^{+}$plants. Broken line-EE $m m$ plants as compared with $E E m^{+} m^{+}$plants. Bold lines show statistically significant changes. 
Table 2. $\mathrm{F}_{2}$ variances of heading dates in crosses between $E$ lines as compared with those of the parents (diagonal)

\begin{tabular}{c|cccccc}
\hline \hline Parental genotype & $E^{\mathrm{a}(10)}$ & $E^{\mathrm{a}(20)}$ & $E^{\mathrm{b}(10)}$ & $E^{\mathrm{b}(20)}$ & $E^{r(5)}$ & $E^{\mathrm{X}(5)}$ \\
\cline { 1 - 6 } & 0.93 & & & & & \\
$E^{\mathrm{a}(10)}$ & $3.68^{* *}$ & 0.94 & & & & \\
$E^{\mathrm{a}(20)}$ & $2.81^{* *}$ & & 1.26 & & & \\
$E^{\mathrm{b}(10)}$ & & $4.22^{* *}$ & 1.36 & 1.04 & & \\
$E^{\mathrm{b}(20)}$ & & $3.80^{* *}$ & & $5.63^{* *}$ & 2.28 & \\
$E^{r(5)}$ & & $2.34^{* *}$ & & $1.46^{*}$ & $4.76^{* *}$ & 0.99 \\
$E^{\mathrm{X}(5)}$ & & &
\end{tabular}

$*$, ** Significantly larger than the variance of parents at $5 \%$ and $1 \%$ level, respectively, by $\mathrm{F}$ test. (Experiment in 1973 winter)

Table 3. Occurrence of early-heading $\mathrm{F}_{2}$ offtypes in crosses between "late-heading sib lines" and maximum likelihood estimation of recombination values between assumed subloci

\begin{tabular}{ccccc}
\hline \hline \multicolumn{1}{c}{ Cross } & $\begin{array}{c}\text { No. of } \mathrm{F}_{2} \\
\text { plants observed }\end{array}$ & $\begin{array}{c}\text { Early } \\
\text { offtypes }\end{array}$ & $\begin{array}{c}\text { Recombination } \\
\text { value }(\%)\end{array}$ & $\begin{array}{c}\text { Subloci } \\
\text { recombined }\end{array}$ \\
\hline $\mathrm{A} 3_{7} \mathrm{~L} \times \mathrm{B} 96_{15} \mathrm{~L}$ & 1,380 & 7 & 0.51 & $E_{4^{\prime}}-E_{2^{\prime}}$ \\
$\mathrm{A} 3_{7} \mathrm{~L} \times \mathrm{B} 96_{20} \mathrm{~L}$ & 255 & 1 & 0.39 & $E_{4^{\prime}}-E_{3^{\prime}}$ \\
$\mathrm{A} 3_{7} \mathrm{~L} \times \mathrm{A} 3_{20} \mathrm{~L}$ & 264 & 2 & 0.79 & $E_{4^{\prime}}-E_{1^{\prime}}$ \\
$\mathrm{B} 96_{7} \mathrm{~L} \times \mathrm{B} 96_{15} \mathrm{~L}$ & 339 & 1 & 0.30 & $E_{1^{\prime}}-E_{2^{\prime}}$ \\
$\mathrm{B} 96_{7} \mathrm{~L} \times \mathrm{I} 190_{5} \mathrm{~L}$ & 337 & 3 & 0.90 & $E_{1^{\prime}}-E_{5^{\prime}}$ \\
$\mathrm{B} 96_{15} \mathrm{~L} \times \mathrm{I} 190_{5} \mathrm{~L}$ & 505 & 3 & 0.59 & $E_{2^{\prime}}-E_{5}{ }^{\prime}$ \\
\hline
\end{tabular}

(Experiments in 1971 summer to 1973 summer)

Table 4. Distribution of heading dates in "late-heading sib lines" and their hybrid deriatives

\begin{tabular}{|c|c|c|c|c|c|c|c|c|c|c|}
\hline \multirow[b]{2}{*}{ Line } & \multirow[b]{2}{*}{ Genotype } & \multicolumn{7}{|c|}{ Heading, September (1973) } & \multirow[b]{2}{*}{$\begin{array}{l}\text { No. of } \\
\text { plants }\end{array}$} & \multirow[b]{2}{*}{ Mean $\pm \sigma$} \\
\hline & & 15 & 18 & 21 & 24 & 27 & 30 & $\begin{array}{c}33 \quad 36 \\
\text { (Oct.) }\end{array}$ & & \\
\hline T65 & $e / e$ & & & & 3 & 30 & 17 & 3 & 53 & $28.5 \pm 1.85$ \\
\hline $\mathrm{B} 96_{15}$ & $E^{\mathrm{b}(15)} / E^{\mathrm{b}(15)}$ & & 11 & 14 & 5 & & & & 30 & $20.4 \pm 1.79$ \\
\hline $\mathrm{I} 190_{5}$ & $E^{\mathrm{X}(5)} / E^{\mathrm{X}(5)}$ & 17 & 26 & 10 & & & & & 53 & $17.4 \pm 1.38$ \\
\hline $\mathrm{B} 96_{15} \mathrm{~L}$ & $E_{4}^{\prime} / E_{4}^{\prime}$ & & & & 7 & 49 & 8 & 2 & 66 & $27.6 \pm 1.79$ \\
\hline $\mathrm{B} 96_{7} \mathrm{~L}$ & $E_{5}^{\prime} / E_{5}^{\prime}$ & & & & 4 & 49 & 9 & & 62 & $27.6 \pm 1.42$ \\
\hline $\mathrm{I} 190_{5} \mathrm{~L}$ & $E_{1}^{\prime} / E_{1}^{\prime}$ & & & & & 33 & 28 & 1 & 62 & $28.9 \pm 1.39$ \\
\hline $\mathrm{F}_{3}, \mathrm{BB} 11-5$ & $\left(E_{4}^{\prime}+E_{5}^{\prime}\right) / e^{\prime 1)}$ & 12 & 11 & & & 5 & 3 & & 31 & \\
\hline $\mathrm{F}_{3}, \mathrm{BI} 2$ & $\left(E_{1}^{\prime}+E_{5}^{\prime}\right) / e^{\prime 2)}$ & 6 & 18 & 32 & 23 & 25 & 26 & 3 & 147 & $\begin{array}{l}6 \text { non-heading } \\
\text { off-types }\end{array}$ \\
\hline $\mathrm{F}_{3}, \mathrm{BI} 14$ & $\left(E_{1}^{\prime}+E_{4}^{\prime}\right) / e^{\prime 3)}$ & & 8 & 10 & 4 & 3 & 13 & 7 & 49 & $\begin{array}{l}4 \text { non-heading } \\
\text { off-types }\end{array}$ \\
\hline
\end{tabular}

1), 2) and 3): Heterozygous $F_{3}$ lines from early-heading $F_{2}$ segregants.

1) $\mathrm{B} 96_{15} \mathrm{~L} \times \mathrm{B} 96_{7} \mathrm{~L}$; 2) $\mathrm{B} 96_{7} \mathrm{~L} \times \mathrm{I} 190_{5} \mathrm{~L}$; 3) $\mathrm{B} 96_{15} \mathrm{~L} \times \mathrm{I} 190_{5} \mathrm{~L}$

4) Plants which did not head until October 10 occurred. 
somewhat larger than the parental variances. When they were inter-crossed, the $F_{1}$ plants were of parental late-heading type, but the $\mathrm{F}_{2}$ populations contained a few earlyheading segregants (like the plants with an $E$ gene) with a frequency less than one percent (Table 3). The $F_{3}$ lines from such $F_{2}$ offtypes in many cases showed a 3 early: 1 late segregation, but some showed more complicated patterns of segregation. Namely, a few very late (much later than T65) offtypes occurred and the distribution of heading dates appeared to be continuous; some examples are shown in Table 4.

From among the $\mathrm{F}_{4}$ lines derived from the early-heading $\mathrm{F}_{2}$ offtypes (from intercrosses between late-heading sib lines), those homozygous for earliness were selected and were crossed with $E$ lines. The $\mathrm{F}_{1}$ and a majority of $\mathrm{F}_{2}$ plants showed the early heading time as of the $E$ lines, but there were again a few very late and very early (earlier than $E$ lines) $\mathrm{F}_{2}$ segregants. All these plants had the same morphological features as of $\mathrm{T} 65$.

Even though efforts were made to keep the materials free from contamination, the possibility that the early-heading $\mathrm{F}_{2}$ offtypes found from crosses between late-heading sib lines were due to outcrossing of the $F_{1}$ plants can not be ruled out. However, no such early-heading offtypes were found at all in the selfed progeny of late-heading sib lines. Also the occurrence of very late plants can not be explained by outcrossing, since there were no such plants in and nearby the experimental field. It may be assumed that the offtypes have resulted from a certain internal mechanism.

The frequencies of the $\mathrm{F}_{2}$ offtypes are too high to consider them mutants. A more plausible hypothesis may be that the $E$ locus represents a region containing different subloci (designated as $E^{\prime} \mathrm{s}$ in Table 3 and Fig. 2). The late-heading sib lines would each have a different part of the region, and when a sufficient number of subloci are combined in cis form by intralocus recombination, complementation would take place to restore the function of $E$. For instance, assuming that a late-heading sib line has $E_{1}{ }^{\prime}$, the other has $E_{2}{ }^{\prime}$, and at least two subloci are necessary for advancing heading, a gamete having $E_{1}{ }^{\prime}$ and $E_{2}{ }^{\prime}$ will be expected to arise after a crossing-over between $E_{1}{ }^{\prime}$ and $E_{2}{ }^{\prime}$. Then, another recombinant simultaneously produced would be recessive at both subloci. Based on this hypothesis, recombination values between subloci were estimated from the $\mathrm{F}_{2}$ data in Table 3 by the maximum likelihood technique, and a tentative map of the $E$ region was depicted (Fig. 2). The largest estimate of distance was 0.9 percent.

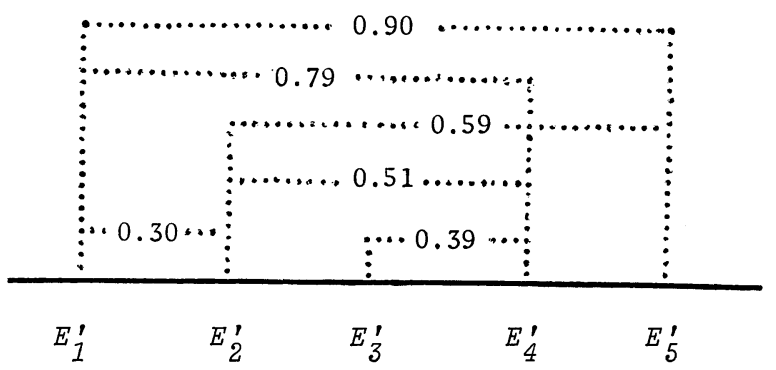

Fig. 2. A tentative map of the $E$ region. $E^{\prime}$ denotes a sublocus. 
It may be inferred, further, that in hybrids between lines with different subloci, unequal crossing-over can produce various pseudoalleles which give rise to very early and very late offtypes.

Interaction between $E$ and $m$. As mentioned, genes $m^{\mathrm{a}}$ (from $\mathrm{A}$ ) and $m^{\mathrm{b}}$ (from $\mathrm{B}$ ) are at a locus independent of $E$ (remaining undetermined), and similarly enhance the heading-advancing effect of $E$ (Tsai and Oka 1970). Repeated tests failed to detect a significant difference between the two genes. When $m$ was combined with $e$, the $e e \mathrm{~mm}$ plants had a heading date a few days earlier than that of $e e m^{+} m^{+}$plants (T65) in the winter season, but had the same heading date as of T65 in the summer season (Table 5). When $m$ was combined with $E$, the heading date of $E E m m$ plants was earlier than that of $E E m^{+} m^{+}$plants by about 10 (winter) to 6 (summer) days.

The dominance relation between $m$ and $m^{+}$also differed according to the cropping seasons (Table 5). When combined with $E^{\mathrm{b}}, m^{\mathrm{b}}$ was incompletely recessive in winter $(d / a=0.60)$ and incompletely dominant over $m^{+}(d / a=-0.42)$ in the summer season. When combined with $e, m^{\mathrm{b}}$ was incompletely dominant in the winter season; in the summer, it has no recognizable effect as already mentioned. As all these lines are insensitive to photoperiod, the seasonal differences observed in the effect of $m$ may be attributed to a difference in temperature; the average temperature around the time of floral initiation in the winter season (early April) is about $20^{\circ}-22^{\circ} \mathrm{C}$, and that in the summer season (middle August) is $28^{\circ}-29^{\circ} \mathrm{C}$.

A comparison of $E^{\mathrm{a}}$ and $E^{\mathrm{b}}$ regarding their interaction with $m^{\mathrm{b}}$ was reported earlier (Tsai and Oka 1970). The heading date of A24 having $E^{\mathrm{a}(7)}$ and $m^{\mathrm{b}}$ was several days earlier than that of B20 with $E^{\mathrm{b}(7)}$ and $m^{\mathrm{b}}$. To obtain more data on the differential

Table 5. Epistatic effects of genes $E^{\mathrm{b}}$ and $m^{\mathrm{b}}$ on heading date in homoand heterozygotes

\begin{tabular}{|c|c|c|c|}
\hline \multirow[t]{2}{*}{ Line } & \multirow[t]{2}{*}{ Genotype } & \multicolumn{2}{|c|}{$\begin{array}{l}\text { Days to heading, shown by difference } \\
\text { from that of } \mathrm{T} 65\end{array}$} \\
\hline & & Winter & Summer \\
\hline \multicolumn{4}{|c|}{ Homozygotes, mean for 5 years, 1965-1969: } \\
\hline T65 & $e / e m^{+} / m^{+}$ & $0(120.7)$ & $0(83.0)$ \\
\hline $\mathrm{B} 96_{7}$ & $E^{\mathrm{b}} / E^{\mathrm{b}} m^{+} / m^{+}$ & -8.6 & -9.0 \\
\hline $\mathrm{B} 172_{7}$ & $e / e m^{\mathrm{b}} / m^{\mathrm{b}}$ & -5.2 & +1.3 \\
\hline $\mathrm{B} 2 \mathrm{O}_{7}$ & $E^{\mathrm{b}} / E^{\mathrm{b}} m^{\mathrm{b}} / m^{\mathrm{b}}$ & -18.7 & -15.6 \\
\hline \multicolumn{2}{|c|}{ Standard error } & 0.48 & 0.58 \\
\hline
\end{tabular}

\begin{tabular}{cllll}
\hline Heterozygotes, difference from mid-parent value, 1967 data: & & \\
$\mathrm{T} 65 \times \mathrm{B} 172_{7}$ & $e / e m^{+} / m^{\mathrm{b}}$ & $-2.5(-0.59) 1)$ & -0.1 & $(-0.15)$ \\
$\mathrm{B} 96_{7} \times \mathrm{B} 20_{7}$ & $E^{\mathrm{b}} / E^{\mathrm{b}} m^{+} / m^{\mathrm{b}}$ & $+1.4(+0.60)$ & $-1.7(-0.42)$ \\
$\mathrm{B} 172_{7} \times \mathrm{B} 96_{7}$ & $e / E^{\mathrm{b}} m^{+} / m^{+}$ & $-6.5(-0.94)$ & $-4.5(-1.46)$ \\
$\mathrm{B} 20_{7} \times \mathrm{B} 172_{7}$ & $e / E^{\mathrm{b}} m^{\mathrm{b}} / m^{\mathrm{b}}$ & $-5.7(-0.92)$ & $-7.6(-1.00)$
\end{tabular}

1) Falconer's $(1960$, p. 113) $d / a$ in parenthesis, given by

$$
\frac{\bar{F}_{1}-\frac{1}{2}\left(\bar{P}_{1}+\bar{P}_{2}\right)}{\frac{1}{2}\left(\bar{P}_{1}-\bar{P}_{2}\right)}
$$


epistatic effects of $E$ alleles with the $m$ gene, different $E$ lines were crossed to two tester lines having $e$ and $m$, and the $\mathrm{F}_{2}$ distributions of days to heading were observed (Table 6). Since the distributions were continuous, they were each compared with an expected distribution as follows: It was assumed that $E$ was dominant, $m$ was recessive, and the distribution in each phenotypic class was normal and represented by the mean and standard deviation of parental lines. On this assumption, expected distributions were calculated on the basis of $3(E m): 9\left(E m^{+}\right): 4\left(e m\right.$ and $\left.e m^{+}\right)$ratio for each of the $\mathrm{F}_{2}$ populations. In 11 out of $13 \mathrm{~F}_{2}$ populations thus examined, chi-square tests gave a good agreement between the expected and observed distributions; inconsistency in the remaining two crosses appeared to be due to incomplete recessiveness of the $m$ gene. Then, the mean heading date of earliest-heading $3 / 16$ or 18.8 percent of $\mathrm{F}_{2}$ plants was computed in each cross to estimate the epistatic effects of different $E$ alleles with the same $m$ gene. The results obtained by using two testers (A4-58 with

Table 6. Comparison of $E-m$ epistasis among different $E$ alleles: The heading date of earliest $18.8 \%(=3 / 16) \mathrm{F}_{2}$ plants $(E m)$ as shown by its difference from that of $E$ lines $\left(E m^{+}\right)$

\begin{tabular}{|c|c|c|c|c|c|}
\hline \multirow{2}{*}{$\begin{array}{l}\text { Parental } \\
\text { line }\end{array}$} & \multirow{2}{*}{ Genotype } & \multicolumn{2}{|c|}{$\begin{array}{l}\text { Crossed with A4-58 }\left(e m^{\text {a }}\right) \\
\text { (seeded Jan. 28, 1974) }\end{array}$} & \multicolumn{2}{|c|}{$\begin{array}{l}\text { Crossed with B40-20 }\left(e m^{\text {b }}\right) \\
\quad(\text { seeded July } 17,1974)\end{array}$} \\
\hline & & Heading date & No. of plants & Heading date & No. of plants \\
\hline \multicolumn{6}{|l|}{ Line means: } \\
\hline$E$ lines & $E m^{+}$ & $0(=111.5)^{1)}$ & 375 & $0(=80.8)^{1)}$ & 547 \\
\hline A4-58 & $e m^{\mathrm{a}}$ & +11.5 & 48 & & \\
\hline B 40-20 & $e m^{\mathrm{b}}$ & & & +11.1 & 49 \\
\hline T65 & $e m^{+}$ & +13.1 & 29 & +11.5 & 47 \\
\hline
\end{tabular}

Mean for earliest $18.8 \% \mathrm{~F}_{2}$ plants:

\begin{tabular}{|c|c|c|c|c|c|}
\hline & (All with $m^{+}$) & $(\mathrm{A} 4-58 \times)$ & Total $\mathrm{F}_{2}$ plants & $(\mathrm{B} 40-20 \times)$ & Total $F_{2}$ plants \\
\hline $\mathrm{A} 3_{7}$ & $E^{\mathrm{a}(7)}$ & -7.8 & 201 & -11.1 & 173 \\
\hline $\mathrm{A} 3_{10}$ & $E^{\mathrm{a}(10)}$ & -9.7 & 140 & -15.9 & 172 \\
\hline $\mathrm{A} 3_{20}$ & $E^{\mathbf{a}(20)}$ & -7.0 & 244 & -12.0 & 188 \\
\hline $\mathrm{B} 96_{7}$ & $E^{\mathrm{b}(7)}$ & -4.7 & 247 & -5.9 & 174 \\
\hline$B 96_{10}$ & $E^{\mathrm{b}(10)}$ & -5.8 & 246 & -7.7 & 175 \\
\hline$B 96_{20}$ & $E^{\mathrm{b}(20)}$ & -10.0 & 247 & -17.4 & 188 \\
\hline $\mathrm{I} 123$ & $E r(0)$ & -6.2 & 249 & -5.9 & 185 \\
\hline $\mathrm{I} 123_{2}$ & $E^{r(2)}$ & -6.1 & 158 & -7.4 & 175 \\
\hline $\mathrm{I} 123_{5}$ & $E^{r(5)}$ & -9.3 & 191 & -11.9 & 195 \\
\hline I190 & $E^{\mathrm{X}(0)}$ & -5.5 & 245 & -5.7 & 175 \\
\hline $\mathrm{I} 190_{2}$ & $E^{\mathrm{X}(2)}$ & -4.4 & 147 & -6.2 & 176 \\
\hline $\mathrm{I} 190_{5}$ & $E^{\mathrm{X}(5)}$ & -5.0 & 241 & -7.3 & 190 \\
\hline \multirow[t]{3}{*}{ AB3 } & $E_{(2)}^{\prime}-E_{(4)}^{\prime}$ & -9.4 & 245 & -13.3 & 173 \\
\hline & $\mathrm{LSD}^{2)} \quad 5 \%$ & 1.04 & & 0.99 & \\
\hline & $1 \%$ & 1.39 & & 1.32 & \\
\hline
\end{tabular}

1) No. of days to heading.

2) For difference between means for 40 plants. 
$m^{\mathrm{a}}$ and B40-20 with $m^{\mathrm{b}}$ ) consistently showed that $E^{\mathrm{a}(7)}$ as well as $E^{\mathrm{a}(10)}$ had a stronger effect than $E^{\mathrm{b}(7)}$ and $E^{\mathrm{b}(10)}$. In $E^{\mathrm{b}}$ and $E^{r}$, "purification" by backcrossing tended to increase the $E-m$ epistatic effect (Table 6; Fig. 1). A "synthesized" $E$ allele from AB3 (from a cross of late-heading sib lines, $\mathrm{A} 3_{7} \mathrm{~L} \times \mathrm{B} 96_{15} \mathrm{~L}$ ) showed a strong epistatic effect with $m$ comparable to that of $E^{\text {a }}$. It may be concluded that the $E$ alleles significantly differ in the magnitude of interaction with the $m$ gene.

\section{DISCUSSION}

The results of the present experiment suggested that the $E$ locus in rice could be a region comprising various subloci. A large number of examples of so-called compound loci are found in the literature of genetics. The $R$ locus controlling anthocyanin formation in maize is known to consists of two subloci, $P$ for general pigmentation and $S$ for pigmentation in the aleurone layer of endosperm (Stadler and Emmerling 1956). Further, according to Brink et al. (1968), a particular site exists in the $R$ locus in addition to the above subloci, and heterozygotes for certain $R$ alleles exhibit the phenomenon of so-called paramutation. Thus, some compound loci seem to contain not only subloci with similar effects but also particular mutant sites. The $w x$ locus of maize is known to be a complementation group of several gene sites and their recombination gives rise to non-waxy pollen grains and plants (Nelson 1962, 1968). A similar finding was also reported for the $w x$ (glutinous) locus of rice (Li et al. 1965).

In Drosophila melanogaster, more than eight compound loci each comprising a number of recombinationary separable subloci or sites have been known (Lindsley and Grell 1967). But a region covered by a compound locus is usually of the order of 0.1 percent recombination value in Drosophila as well as in the above-mentioned cases in plants. In the present experiment, the $E$ locus seemed to occupy a region of at least 0.9 percent. An example similar to the present case in this respect has been found in the silkworm (Bombyx mori), where the $E$ region on the sixth chromosome had more than 20 alleles concerning different subloci (Dr. M. Tsujita, personal communication). Of them, the recombination value between $E^{\mathrm{H}}$ and $E^{\mathrm{Kp}}$ was about 0.7 perccent (Tsujita 1955). The larvae with $E^{\mathrm{H}} E^{\mathrm{Kp}} /++$ expressed the same phenotype as of $E^{\mathrm{El}}$; the homozygotes for $E^{\mathrm{El}}$ were inviable whereas those for $E^{\mathrm{H}} E^{\mathrm{Kp}}$ were viable. It is difficult to estimate how many gene cistrons exist in the $E$ region of rice or of silkworm. Possibly, a number of similar cistrons are repeated in the region. The evolutionary significance of tandem duplication has been advocated by Ohno (1970). When a gene locus is duplicated, mutation and unequal crossing-over may give rise to pseudoalleles with variously readjusted functions.

In the present experiment, two radiation-induced dominant alleles, $E^{r}$ and $E^{\mathrm{x}}$, were found to exert almost the same action as of the alleles of spontaneous origin, $E^{\mathrm{a}}$ and $E^{b}$. Lines with the induced alleles also produced, in the same manner as those with $E^{\text {a }}$ or $E^{\text {b }}$, "late-heading sib lines" which were deemed to have a part of the $E$ region. A compound locus can not be created by a single hit of ionizing radiation. The mutation producing an $E$ allele may be explained by assuming that the region contains an 
element which suppresses the activity of the whole region. Then, if the particular element was deleted or damaged, the region would be activated to give rise to a dominant $E$ allele. This assumption implies that the $e$ gene in T65 is ready to evolve earliness genes.

It was found that with "purification" of the isogenic lines by backcrossing, the heading-advancing effect of the $E$ locus tended to be mitigated. This can be explained assuming that some subloci at the fringe of the region have been removed by recombination. But it is more difficult to explain why the $E-m$ epistasis appeared to be intensified with purification. Perhaps, the subloci in the $E$ region differently react to some message from the $m$ gene.

The major function of the $E$ region seems to be regulation of the time schedule of floral initiation and subsequent organ development. The $E$ region of the silkworm also seems to control development. One may infer that such a region in higher organisms contains a series of structural and regulatory genes. According to Nei (1968), interacting genes tend to be clustered to form a complex locus because of its selective advantage. In rice, perhaps, the $E$ region has helped the species to evolve earlymaturing genotypes which are adapted to the climate of temperate zones.

In addition to the $E$ locus, there are other loci controlling heading time in rice. One of them, $m$, which was isolated in the genetic background of T65, was found to epistatically intensify the effect of $E$ alleles, the magnitude differing according to $E$ alleles. There can be other loci than $m$ having similar functions, though they are not isolated yet. In the early stage of this work when the materials were not completely isogenic, it was once conceived that there were two modifier loci, $M_{1}$ and $m_{2}$ (Tsai and Oka 1966). Later, $M_{1}$ was neglected as evidence supporting its existence was ambiguous, and the $m_{2}$ was resymbolized $m$. As mentioned before, biometrical analysis of the data suggested that the genes remaining unanalysed would be modifiers exerting a buffering effect when recombined. When isogenic lines with those modifier genes are developed, their effects will be brought out more clearly. On the present situation, it may be concluded that a compound locus with major effect and some modifier genes control the heading time in the cross between T65 and an early-maturing cultivar, and that the effects of the modifier genes are non-additive and environment-dependent.

The breeding of isogenic lines is a time-consuming task. In the present work, the initial crosses were made in 1954. Yet, it may be said that elaborate features of the genetic control of quantitative characters, which can not be worked out by biometrical methods, are brought to light by the use of isogenic lines.

\section{SUMMARY}

By recurrent backcrossing continued up to the $B_{20}$ generation, isogenic lines with earliness genes were established. A pure line of a rice variety, Taichung 65 (abridged as T65, Japonica type, insensitive to photoperiod) was exclusively used as the recurrent parent; two early maturing cultivars from northern China (A) and northern Japan (B) and two radiation-induced early-maturing mutant lines of $\mathrm{T} 65$ were each used as the 
donor parent. The results of crossing experiments with those isogenic lines demonstrated that the earliness genes from different donor parents were at the same locus on the 8th chromosome (symbolized $E$ ), and similarly moved up the time of floral initiation about 7 days and shortened the period from floral initiation to heading by about 3 days. However, when the lines with different $E$ alleles were compared in more detail, they showed significant differences. Evidence was produced showing that the $E$ locus would be a region containing several recombinationary separable subloci and when the "suballeles" were combined in cis form, complementation would restore the function of an $E$ allele. There could also be an element suppressing the function of the whole region and making the recessive allele, $e$, carried by $\mathrm{T} 65$; its mutation may result in induction of dominant $E$ alleles. Slight but significant changes in the effect of $E$ alleles were observed when the isogenic lines were "purified" by backcrossing. Further, isogenic lines having a modifier gene at an independent locus, $m$, were investigated. The $m$ gene intensified the effect of $E$ alleles, the magnitude of the epistatic effect differing according to $E$ alleles. When combined with $e$, the $m$ gene had no effect in summer, but promoted heading several days in the winter season. There can be other modifier genes than $m$ exerting a buffering effect when recombined. A summary of earlier papers on these earliness genes was presented in addition.

\section{ACKNOWLEDGEMENTS}

I am indebted to Dr. H. I. Oka, National Institute of Genetics, Japan, for his collaboration and advices during the course of the experiments and critical review of the manuscript, and to Professor M. Takahashi, Hokkaido University, for kind encouragements and critical reading of the manuscript. Further, I express my sincere thanks to the National Science Council, Republic of China, and the Joint Commission on Rural Reconstruction for their generous financial support.

\section{LITERATURE CITED}

Allard, R. W., 1960 Principles of Plant Breeding. Wiley and Sons, New York. 484pp.

Brink, R. A., E. D. Styles, and J. D. Axtell, 1968 Paramutation: Directed genetic change. Science 159: 161-170.

Chandraratna, M. F., 1955 Genetics of photoperiod sensitivity in rice. J. Genetics 53: 215-223.

Chang, T. T., C. C. Li, and B. S. Vergara, 1969 Component analysis of duration from seeding to heading in rice by the basic vegetative phase and the photoperiod-sensitive phase. Euphytica 18: $79-91$.

Falconer, D. S., 1960 Introduction to Quantitative Genetics. Oliver and Boyd, London. 365pp.

Kawase, T., and N. Murata, 1958 Studies on the relationship between genetic and environmental effects on character development, 1 . Response of the genes $E_{1}$ and $E_{2}$ to daylength in rice. Japan. J. Breed. 8: 95-99. (in Jap. with Eng. summary)

Li, H. W., S. Wang, and P. Z. Yeh, 1965 A preliminary note on the fine structure analysis of glutinous gene in rice. Bot. Bull. Acad. Sinica 6: 101-105.

Lindsley, D. L., and E. H. Grelle, 1967 Genetic variations of Drosophila melanogaster. Carnegie Institute of Washington, Publ. 627. 471pp.

Mather, K., 1949 Biometrical Genetics. Methuen, London. 162pp. 
Nei, M., 1968 Evolutionary change of linkage intensity. Nature 218: 160-161.

Nelson, O. E., 1962 The waxy locus in maize, I. Intralocus recombination frequency estimates by pollen and by conventional analysis. Genetics 47: 737-742.

Nelson, O. E., 1968 Ditto. II. The location of the controlling element alleles. Genetics 60: 507524.

Ohno, S., 1970 Evolution by Gene Duplication. Springer, Berlin. 160pp.

Stadler, L. J., and M. H. Emmering, 1956 Relation of unequal crossing-over to the interdependence of $R^{\mathrm{r}}$ elements $(\mathrm{P})$ and $(\mathrm{S})^{1,2,3}$. Genetics 41: 124-137.

Takahashi, M., 1964 Linkage groups and gene schemes of some striking morphological characters in Japanese rice. In Rice Genetics and Cytogenetics, Ed. R. F. Chandler, p. 215-236. Elsevier, Amsterdam. 274pp.

Tsai, K. H., and H. I. Oka, 1965 Genetic studies of yielding capacity and adaptability in crop plants, 1. Characters of isogenic lines in rice. Bot. Bull. Acad. Sinica 6: 19-31.

Tsai, K. H., and H. I. Oka, 1966 Ditto. 2. Analysis of genes controlling heading time in Taichung 65 and other rice varieties. Bot. Bull. Acad. Sinica 7: 54-70.

Tsai, K. H., and H. I. Oka, 1968 Ditto. 3. Further observations on the effects of an earliness gene, $E$, in the genetic background of a rice variety, Taichung 65. Bot. Bull. Acad. Sinica 9: 75-78.

Tsai, K. H., and H. I. Oka, 1970 Ditto. 4. Effects of an earliness gene, $m^{\text {b }}$, in the genetic background of a rice variety, Taichung 65. Bot. Bull. Acad. Sinica 11: 16-26.

Tsai, K. H., 1971a Comparison between radiation-induced and isogenic early-maturing lines of a rice variety, Taichung 65. SABRAO Newsletter 3: 89-100.

Tsai, K. H., 1971b Genetic studies on heading date and other characters of two crosses between Taichung 65 and two early strains in rice. J. Agric. Assoc. China, N.S. 74: 7-18. (in Chinese with Eng. summary)

Tsai, K. H., 1972 Studies on earliness genes of rice by the use of isogenic lines. Doctoral thesis submitted to Hokkaido University, Japan. 179pp. (in Jap. with Eng. summary)

Tsai, K. H., 1973 Comparison of intra-allelic structure related to the major earliness genes involving in isogenic and radiation-induced early-maturing lines of a rice variety, Taichung $65 . \mathrm{J}$. Agric. Assoc. China, N.S. 84: 23-47. (in Chinese with Eng. summary)

Tsai, K. H., 1974 Effects of an earliness gene, E, on organ development and adaptability in the genetic background of a rice variety, Taichung 65. J. Agric. Assoc. China, N.S. 87: 1-20. (in Chinese with Eng. summary)

Tsai, K. H., 1975 Studies on gene interaction occurred within an earliness complex locus in rice. Proc. Nat. Sci. Council, Repb. China 8 (2): 227-236. (in Chinese with Eng. summary)

Tsujita, M., 1955 On the crossing-over between $E^{\mathrm{H}}$ and $E^{\mathrm{Kp}}$ of the $E$ allelic series in the silkworm. Japan. J. Genet. 30: 227-235. (in Jap. with Eng. summary)

Yu, C. J., and Y. T. Yao, 1967 Genetische Studien beim Reis, 3. Über die Vererbung der Photoperiodizität. Bot. Bull. Acad. Sinica 8 (sp. no.): 364-389. (in German) 